\title{
Making sure there's a "give" associated with the "take": producing and using open-source software in big pharma
}

\author{
Gregory Landrum ${ }^{*}$, Richard Lewis ${ }^{1}$, Andrew Palmer $^{2}$, Nikolaus Stiefl ${ }^{1}$, Anna Vulpetti ${ }^{1}$ \\ From 6th German Conference on Chemoinformatics, GCC 2010 \\ Goslar, Germany. 7-9 November 2010
}

In contrast to bioinformatics, open-source software is not as widely used in the pharmaceutical industry for molecular modeling and cheminformatics. Typical reasons given for this include problems with code quality, stability, and long-term support for the software (somehow this is less of a concern with bioinformatics software... kind of makes one think). Recently, our group has started making heavy use of an open-source cheminformatics toolkit RDKit [1] in our production environment. Importantly, we are not just acting as consumers of open-source software - we are active members of the open-source community and have support from management to contribute code back to the project.

In this presentation we will provide a brief overview of the RDKit itself and then present a number of case studies of how we have made use of this open-source platform. Examples will include using the toolkit for method development [2,3], integration with proprietary tools, and some recent (and upcoming) contributions to the open-souce community, including a database cartridge for fast and flexible similarity searching in the open-source PostgreSQL database [4], and adding support for the RDKit within the open-source pipelining platform Knime [5]. We will finish with a discussion of some practical aspects of working on and with opensource tools in a large research organization.

\section{Author details}

${ }^{1}$ Novartis Institutes for BioMedical Research, Basel, $\mathrm{CH}-4002$, Switzerland. ${ }^{2}$ Novartis Institutes for BioMedical Research, Cambridge MA, 02139, USA.

* Correspondence: gregory.landrum@novartis.com

${ }^{1}$ Novartis Institutes for BioMedical Research, Basel, CH-4002, Switzerland Full list of author information is available at the end of the article
Published: 19 April 2011

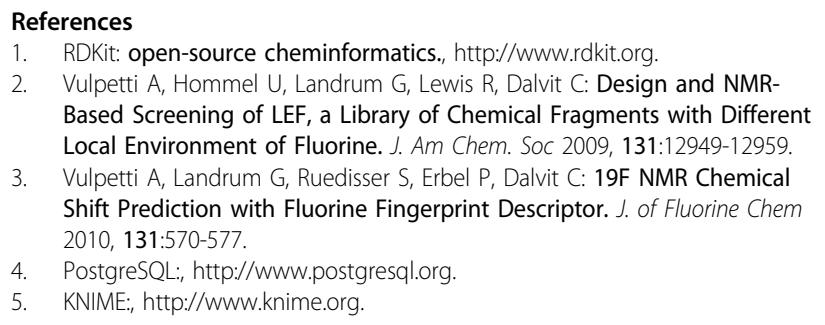
Based Screening of LEF, a Library of Chemical Fragments with Different Local Environment of Fluorine. J. Am Chem. Soc 2009, 131:12949-12959.

3. Vulpetti A, Landrum G, Ruedisser S, Erbel P, Dalvit C: 19F NMR Chemical Shift Prediction with Fluorine Fingerprint Descriptor. J. of Fluorine Chem 2010, 131:570-577.

4. PostgreSQL:, http://www.postgresql.org.

5. KNIME:, http://www.knime.org.

\section{doi:10.1186/1758-2946-3-S1-03}

Cite this article as: Landrum et al:: Making sure there's a "give"

associated with the "take": producing and using open-source software in big pharma. Journal of Cheminformatics 2011 3(Suppl 1):03.

\section{Publish with ChemistryCentral and every scientist can read your work free of charge \\ "Open access provides opportunities to our colleagues in other parts of the globe, by allowing anyone to view the content free of charge." \\ W. Jeffery Hurst, The Hershey Company. \\ - available free of charge to the entire scientific community \\ - peer reviewed and published immediately upon acceptance \\ - cited in PubMed and archived on PubMed Central \\ - yours - you keep the copyright \\ Submit your manuscript here: \\ http://www.chemistrycentral.com/manuscript/

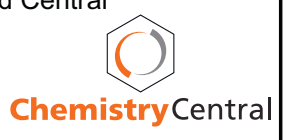

